\title{
Vedolizumab treatment for immune checkpoint inhibitor-induced enterocolitis
}

\author{
Viktoria Bergqvist $^{1} \cdot$ Erik Hertervig $^{1,3} \cdot$ Peter Gedeon $^{1} \cdot$ Marija Kopljar $^{1}$. \\ Håkan Griph ${ }^{6} \cdot$ Sara Kinhult ${ }^{4,5}$ - Ana Carneiro ${ }^{4,5}$ - Jan Marsal ${ }^{1,2,3}$
}

Received: 16 October 2016 / Accepted: 27 January 2017 / Published online: 15 February 2017

(C) The Author(s) 2017. This article is published with open access at Springerlink.com

\begin{abstract}
Immune checkpoint inhibitors (ICPI), such as ipilimumab [anti-cytotoxic T-lymphocyte antigen-4 (CTLA-4) antibody] and nivolumab or pembrolizumab [anti-programmed cell death protein-1 (PD-1) antibodies], improve survival in several cancer types. Since inhibition of CTLA-4 or PD-1 leads to non-selective activation of the immune system, immune-related adverse events (irAEs) are frequent. Enterocolitis is a common irAE, currently managed with corticosteroids and, if necessary, anti-tumor necrosis factor- $\alpha$ therapy. Such a regimen carries a risk of serious side-effects including infections, and may potentially imply impaired antitumor effects. Vedolizumab is an anti-integrin $\alpha 4 \beta 7$ antibody with gut-specific immunosuppressive effects, approved for Crohn's disease and ulcerative colitis. We report a case series of seven patients with metastatic melanoma or lung cancer, treated with vedolizumab off-label for ipilimumab- or nivolumabinduced enterocolitis, from June 2014 through October 2016. Clinical, laboratory, endoscopic, and histologic data
\end{abstract}

Jan Marsal

jan.marsal@med.lu.se

1 Department of Gastroenterology, Skane University Hospital, 22185 Lund, Sweden

2 Immunology Section, Department of Experimental Medical Science, Lund University, Lund, Sweden

3 Section of Medicine, Department of Clinical Sciences, Lund University, Lund, Sweden

4 Department of Oncology, Skane University Hospital, Lund, Sweden

5 Division of Oncology and Pathology, Department of Clinical Sciences, Lund University, Lund, Sweden

6 Department of Respiratory Medicine, Skane University Hospital, Lund, Sweden were analyzed. Patients initially received corticosteroids but were steroid-dependent and/or partially refractory. One patient was administered infliximab but was refractory. The median time from onset of enterocolitis to start of vedolizumab therapy was 79 days. Following vedolizumab therapy, all patients but one experienced steroid-free enterocolitis remission, with normalized fecal calprotectin. This was achieved after a median of 56 days from vedolizumab start, without any vedolizumab-related side-effects noted. The patient in whom vedolizumab was not successful, due to active ulcerative colitis, received vedolizumab prophylactically. This is the first case series to suggest that vedolizumab is an effective and well-tolerated therapeutic for steroid-dependent or partially refractory ICPI-induced enterocolitis. A larger prospective study to evaluate vedolizumab in this indication is warranted.

Keywords Ipilimumab $\cdot$ Nivolumab $\cdot$ Melanoma · Lung cancer · Immune-checkpoint inhibitor induced enterocolitis · Vedolizumab treatment against irAEs

$\begin{array}{ll}\text { Abbreviations } \\ \text { B } & \text { Blood } \\ \text { CRP } & \text { C-reactive protein } \\ \text { CTLA-4 } & \text { Cytotoxic T-lymphocyte antigen-4 } \\ \text { ECOG } & \text { Eastern cooperative oncology group } \\ \text { ELISA } & \text { Enzyme-linked immunosorbent assay } \\ \text { F } & \text { Fecal } \\ \text { IBD } & \text { Inflammatory bowel diseases } \\ \text { ICPI } & \text { Immune checkpoint inhibitor } \\ \text { irAE } & \text { Immune-related adverse event } \\ \text { MAdCAM-1 } & \text { Mucosal addressin cellular adhesion } \\ & \text { molecule-1 } \\ \text { NLR } & \text { Neutrophil/lymphocyte ratio } \\ \text { P } & \text { Plasma }\end{array}$




\begin{tabular}{|c|c|}
\hline PD-1 & Programmed cell death protein-1 \\
\hline PML & Progressive multifocal \\
\hline & leukoencephalopathy \\
\hline SES-CD & $\begin{array}{l}\text { Simple endoscopic score for Crohn's } \\
\text { disease }\end{array}$ \\
\hline TNF & Tumor necrosis factor \\
\hline UCEIS & $\begin{array}{l}\text { Ulcerative colitis endoscopic index of } \\
\text { severity }\end{array}$ \\
\hline
\end{tabular}

\section{Introduction}

Immune checkpoint inhibitors (ICPIs) have greatly improved possibilities for treatment in oncology. The physiological role of immune checkpoints, such as cytotoxic T-lymphocyte antigen-4 (CTLA-4) and programmed cell death protein-1 (PD-1) which are expressed primarily on $\mathrm{T}$ cells, is to regulate the degree of $\mathrm{T}$ cell activation, to prevent exaggerated immune responses or autoimmunity [1]. CTLA-4 is thought to control initial T cell activation and proliferation in lymph nodes early in an immune response. In contrast, PD-1 regulates T cell activity later in an immune response, at the effector site, i.e. the tumor [1]. Antibodies blocking CTLA-4 (ipilimumab) or PD-1 (nivolumab and pembrolizumab) thus augment the immunological response to tumors through related but distinct mechanisms. Furthermore, it is thought that antibodies to CTLA-4 induce depletion of regulatory $\mathrm{T}$ cells which express CTLA-4 $[1,2]$. These new drugs have shown significant survival benefits in advanced melanoma, non-small cell lung cancer, renal cancer, and squamous head and neck cancer, and their efficacy is being investigated in several other cancers $[1,3]$.

ICPIs expand and/or activate not only tumor-specific $\mathrm{T}$ cells but also numerous other $\mathrm{T}$ cell clones. This may break down peripheral self-tolerance and cause immunerelated adverse events (irAEs). ICPIs have been shown to be associated with a number of irAEs, such as enterocolitis, hepatitis, rash, vitiligo, and hypophysitis [4, 5]. Most irAEs are manageable but they can occasionally be very severe and even fatal as in cases with enterocolitis that leads to intestinal perforation [6-8]. Severe or life-threatening irAEs (grade 3-4) are more common with CTLA-4 blockers (reported rates of 20-27\%) than with PD-1 blockers (13-16\%), whereas with combination treatment the rate rises to around $50 \%[3,8]$. The most common grade 3-4 irAEs with all of the various ICPI regimes are gastrointestinal (i.e. diarrhea, enterocolitis, and hepatitis) [4, 5].

Currently, irAEs are managed in accordance with algorithms that are broadly used but not evidence based [9]. Mild (grade 1) diarrhea/enterocolitis can be managed with symptomatic therapy, but in moderate and severe cases (grade 2-3), corticosteroids are used [4, 5].
If corticosteroids are not sufficient, i.e. lack of response to high-dose corticosteroids (2 $\mathrm{mg} / \mathrm{kg}$ methylprednisolone) within days, more potent immunosuppressive agents such as infliximab [anti-tumor necrosis factor (TNF) $\alpha$ antibody], mycophenylate mofetil, or calcineurin inhibitors are recommended [5].

The level of inflammation in the gut can be measured in several ways. The traditional way is to quantify symptoms, primarily the number of bowel movements per day. This parameter is used to grade ICPI-induced diarrhea. A drawback with using symptoms for quantifying inflammation is that they are indirect and subjective in character. Colonoscopy is the gold standard but is cumbersome to perform repeatedly. An even more stringent measure is the histology of the gut mucosa. Plasma CRP and albumin are used but may be affected by other systemic inflammatory processes. A relatively new measure of gut inflammation, that has high sensitivity and specificity, is the fecal (F) concentration of calprotectin. Calprotectin is a calcium-binding protein derived primarily from neutrophils and activated macrophages [10]. Levels of F-calprotectin have been shown to correlate closely with gastrointestinal inflammation [11].

Blood lymphocyte counts have shown a positive correlation, and the blood neutrophil/lymphocyte ratio (NLR) a negative correlation, with overall survival in several solid tumor diseases, both before and after the onset of ICPI therapy, and both with and without corticosteroid therapy taken into account $[12,13]$. Corticosteroids are known to induce apoptosis in lymphocytes but not neutrophils [14] and to induce demargination of neutrophils from the endovascular lining. Similarly, infliximab functions by inducing apoptosis of activated T-lymphocytes through transmembrane TNF $\alpha$, in addition to inhibiting soluble TNF $\alpha$ [15].

Vedolizumab is a humanized monoclonal $\mathrm{IgG} 1$ antibody against $\alpha 4 \beta 7$ integrin, approved for treatment of Crohn's disease and ulcerative colitis, collectively called inflammatory bowel diseases (IBD) [16, 17]. $\alpha 4 \beta 7$ integrin is expressed primarily on a subset of $\mathrm{CD} 4^{+} \mathrm{T}$ cells and mediates homing of these cells specifically to the gut $[18,19]$. The counter-receptor of $\alpha 4 \beta 7$, mucosal addressin cellular adhesion molecule 1 (MAdCAM-1), is expressed selectively on venule endothelial cells of the gut but not in other organs $[18,20]$. Blocking of $\alpha 4 \beta 7$ integrin thus results in a gut-specific immunosuppression, while the immunity in extraintestinal tissues remains intact [20]. In addition, vedolizumab is specific for the dimer $\alpha 4 \beta 7$ and does not bind to other integrins that comprise the $\alpha 4$ or $\beta 7$ subunit, such as $\alpha 4 \beta 1$ which is important for the homing of lymphocytes to a number of organs [19]. The gut-specific effect of vedolizumab is further illustrated by the fact that there have not been any reports of progressive multifocal leukoencephalopathy (PML) with vedolizumab, in contrast to another integrin-inhibitor, natalizumab, which targets $\alpha 4 \beta 1$ 
in addition to $\alpha 4 \beta 7$, and thus inhibits lymphocyte function systemically [21]. It is well recognized that vedolizumab has a gradual onset of therapeutic effect [22]. This may be explained by the mode-of-action which is inhibition of recruitment of new lymphocytes to the gut mucosa, with less effect on the cells already present in the inflamed gut tissue [20].

Here, we report on seven patients with ICPI-induced enterocolitis, which were either corticosteroid-dependent and/or partially refractory, managed successfully with vedolizumab infusions.

\section{Methods}

Seven patients who had received immunotherapy with either ipilimumab or nivolumab against advanced melanoma $(n=6)$ or non-small cell lung cancer $(n=1)$ between January 2014 and July 2015 at Skane University Hospital, received subsequent treatment with vedolizumab due to IPCI-induced enterocolitis (here defined as inflammation primarily of the colon and distal ileum with or without confirmed inflammation in more proximal segments). The first of these patients was started on vedolizumab therapy in June 2014 and the last in June 2016. The therapy decisions were clinically based and taken by a multidisciplinary team comprising gastroenterologists and oncologists. The patients were, retrospectively, identified and enrolled for review and analysis of medical records. The study was approved by the regional ethics committee in Lund, Sweden (reference No. 2016/624). No patient consent was required as this was a retrospective study. The study was performed in accordance with the ethical standards of the 1964 Helsinki declaration and its later amendments.

All laboratory blood and fecal tests were taken as part of clinical routine. F-calprotectin was measured using a commercially available enzyme-linked immunosorbent assay (ELISA) (Calpro AS). The lower limit of the ELISA was $30 \mathrm{mg} / \mathrm{kg}$; values below this cut-off were estimated as $15 \mathrm{mg} / \mathrm{kg}$. F-calprotectin levels $<50 \mathrm{mg} / \mathrm{kg}$ are normal according to the manufacturer, but studies in IBD have suggested $100 \mathrm{mg} / \mathrm{kg}$ to be a more adequate cut-off level [23].

The degree of diarrhea was graded 1 to 5 in accordance with the Common Terminology Criteria for Adverse Events version 4.0 which grades the increase in number of stools per day above the baseline value [24]: Grade 1, increase of $<4$ stools; grade 2, 4-6 stools; grade 3, $\geq 7$ stools; grade 4 , diarrhea with life-threatening consequences; grade 5, death. Films and pictures from the ileocolonoscopic examinations recorded for clinical purposes, were categorized blindly by an experienced endoscopist into normal, mild, moderate, or severe inflammation, based on global assessment of the most inflamed segment with regards to several parameters including erythema, vascular pattern, granularity, bleeding, and ulceration. In addition, the ileocolonoscopic examinations were scored using the Ulcerative Colitis Endoscopic Index of Severity (UCEIS) [25] and the Simple Endoscopic Score for Crohn's Disease (SES-CD) [26], respectively. These scores were used since a specific endoscopic index for immune-therapy associated enterocolitis does not exist, as yet. The score range for a single intestinal segment is $0-8$ for UCEIS and $0-12$ for SES-CD, and 0-20 for the combination of these. Thresholds defining remission, mild, moderate, and severe disease have yet to be established. However, for UCEIS, it has been suggested that a score of $0-1$ represents remission and 7-8 represents severe disease in the context of ulcerative colitis, whereas the cut-off separating mild from moderate disease remains unclear [27]. Colonic mucosal histopathology was categorized into normal, mild, moderate, or severe inflammation based on global assessment of several parameters including acute and chronic inflammatory infiltration of lamina propria and the epithelium, and architectural disorder.

Performance status was assessed in accordance with the Eastern Cooperative Oncology Group (ECOG) scale ranging from 0 to 5 [28]. Statistical analysis was performed using Prism 6 for Mac OS X version 6.0h (GraphPad Software, Inc.).

\section{Results}

\section{Patient characteristics}

Five patients diagnosed with metastatic melanoma (stage IV) and one with melanoma stage IIIc were treated with ipilimumab. One patient with non-small cell lung cancer stage IV was treated with nivolumab. Patient characteristics are summarized in Table 1. At initiation of ICPI therapy, patient age ranged from 40 to 71 years with a median of 55 years. The male to female ratio was 4:3. Performance status according to the ECOG scale was 0 for three patients and 1 for four patients at initiation of therapy.

Two patients had a history of inflammatory bowel disease. Patient No. 3 had a history of ulcerative colitis that increased in activity after treatment with pembrolizumab. Before this patient was switched to ipilimumab because of tumor progression, she was started on prophylactic vedolizumab treatment. Patient No. 7 had undergone a right hemicolectomy due to Crohn's disease in adolescence, which led to sustained inflammatory remission, and showed no signs of inflammatory bowel disease when nivolumab therapy was started. This patient had previously also been diagnosed with atrial fibrillation, pulmonary embolism, sarcoidosis and chronic obstructive pulmonary disease. 


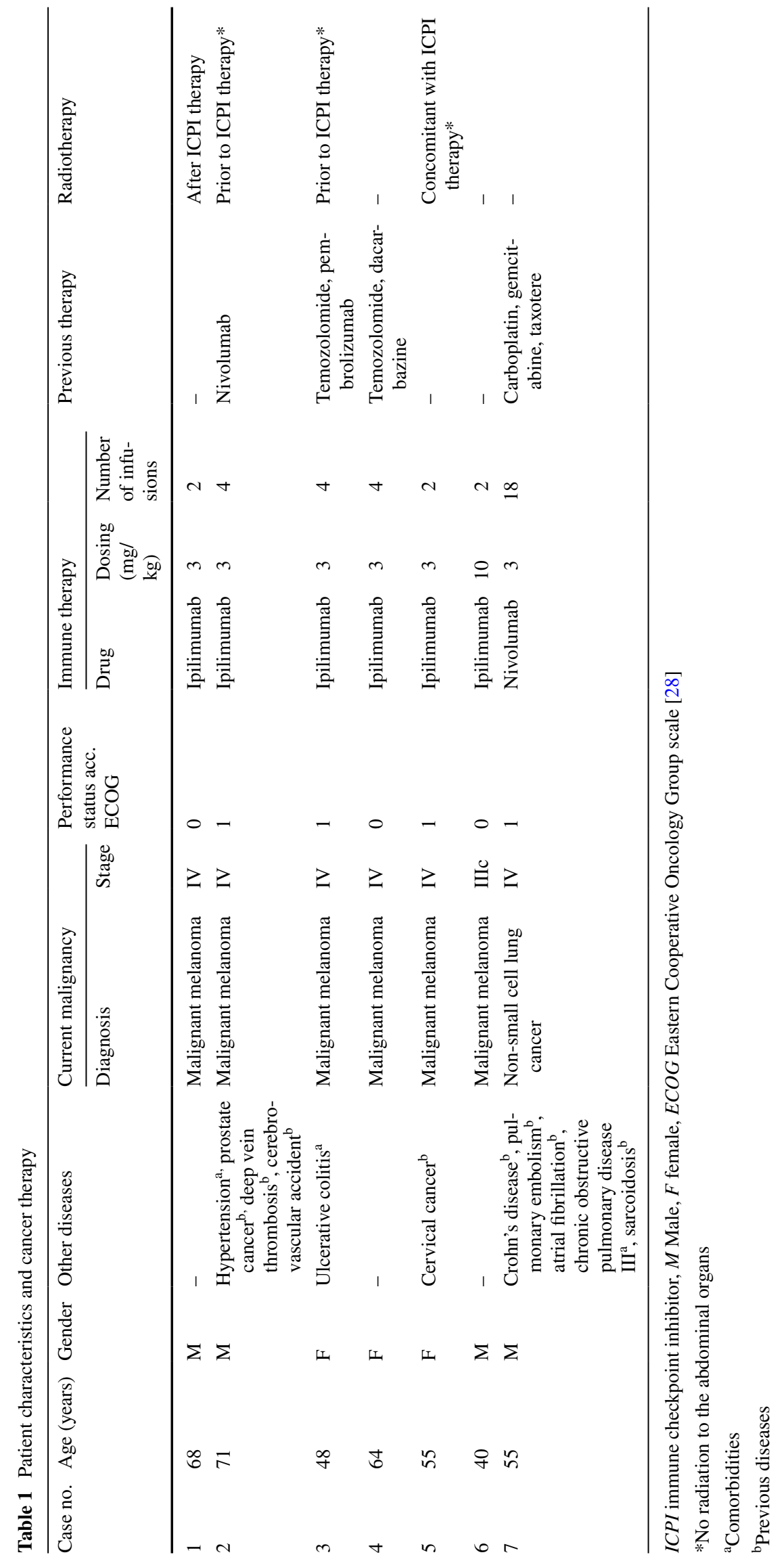


Patients No. 2 and No. 5 had a history of prostate and cervical cancer, respectively.

\section{Cancer therapy}

Ipilimumab or nivolumab were dosed at $3 \mathrm{mg} / \mathrm{kg}$ of body weight with an interval of 3 weeks for ipilimumab and 2 weeks for nivolumab, in all patients except for patient No. 6 who was given $10 \mathrm{mg} / \mathrm{kg}$ body weight of ipilimumab every 3 weeks (Table 1). Between infusions 1 and 2, patient No. 5 received radiation therapy against axillary lymph nodes with 25 Gy in 5 fractions. Four patients had previously received chemotherapy and/or another type of immunotherapy (Table 1). The number of infusions given before onset of enterocolitis symptoms ranged from 2 to 4 for patients receiving ipilimumab, whereas the patient on nivolumab therapy received 18 doses prior to symptom development (Table 1). ICPI therapy was discontinued in all patients upon development of grade 3 enterocolitis with grade 2-3 diarrhea, and the total number of infusions hence equals the number of infusions given before symptom onset.

\section{Diagnosis, management, and evaluation of ICPI-induced enterocolitis}

The median time that elapsed from the first dose of ipilimumab to onset of enterocolitis symptoms was 65 days (range 38-88 days) (Table 2). The median time from the last dose to development of symptoms was 19 days (range 9-27 days) (Table 2). Patient No. 7 who received 18 nivolumab infusions did not develop enterocolitis until 292 days after therapy was commenced. Two patients presented with grade 2 diarrhea, and five patients with grade 3 diarrhea (Table 2). Patient No. 5 developed additional immunerelated adverse events (irAEs) in the form of rash and iritis, but in the other patients diarrhea/enterocolitis were the only irAEs requiring treatment. Bacterial cause for diarrhea was ruled out by means of stool cultures and Clostridium diffcile toxin tests. At diagnosis, all patients were examined by computed tomography scanning. Large and/or small bowel wall thickening was present in five cases, and in two cases the scans was considered inconclusive.

The patients were initially treated with corticosteroids in accordance with international recommendations for treatment of IPCI-induced enterocolitis [4, 5], including intravenous administration of methylprednisolone dosed up to $2 \mathrm{mg} / \mathrm{kg}$ body weight. The enterocolitis that these patients displayed was either partially steroid-refractory (i.e. partial but not complete response) and/or steroid-dependent (i.e. at adequate tapering of high-dose corticosteroids, patients exhibited increased signs of enterocolitis).

Prior to starting vedolizumab therapy, all patients underwent ileocolonoscopy. Endoscopic inflammatory signs were scored in accordance with the UCEIS and SES-CD indexes and an integrated global inflammation categorization was performed. Two patients displayed mild endoscopic inflammation and five displayed moderate inflammation, according to the global endoscopic assessment (Table 2). The mean UCEIS, SES-CD, and combined scores for patients with mild or moderate endoscopic findings are shown in Fig. 1a. Histopathologic evaluation of colonic mucosal biopsies showed mild inflammation in three cases, moderate inflammation in two cases, and severe inflammation in two cases (Table 2). The combined endoscopic scores corresponded well to the histopathologic findings as shown in Fig. 1b.

\section{Vedolizumab treatment for ICPI-induced enterocolitis}

When treated for their ICPI-induced diarrhea/enterocolitis, patients No. 1, 4, 6, and 7 responded to high-dose corticosteroids but were considered steroid-dependent as they relapsed when therapy was tapered in accordance with international recommendations (i.e. tapering scheduled over 4-8 weeks). Patients No. 2, 3, and 5 responded only partially to high-dose corticosteroids and were thus considered partially steroid-refractory (Table 2). Inadequate inflammatory control on corticosteroid therapy despite optimized dosing and repeated retapering attempts, prompted the use of vedolizumab. The median time from onset of enterocolitis to start of vedolizumab was 79 days (range 57-86) (Table 2). Vedolizumab was administered with infusions of $300 \mathrm{mg}$ at time-points 0,2 , and 6 weeks or until clinical and laboratory regression was observed (Table 2). This corresponds to the induction treatment regimen recommended for Crohn's disease and ulcerative colitis. Patient No. 7 initially received infliximab therapy but since this was unsuccessful, vedolizumab was administered. At the start of vedolizumab treatment, patient No. $1,2,4,5$, and 6 displayed grade 1, and patient No. 7 grade 3 diarrhea. In addition, patient No. 6 and 7 had abdominal pain. The number of vedolizumab infusions given was 2 to 4; at the time of the first infusion, the daily dose of prednisolone ranged from 20 to $160 \mathrm{mg}$ with a mean of $78 \mathrm{mg}$ (Table 2). Prednisolone could then be successfully tapered in all of the patients except in patient No. 3. The median time from start of vedolizumab treatment to steroid-free remission from enterocolitis symptoms was 56 days (range 52-92 days). No side effects related to vedolizumab treatment were observed (Table 2).

Patient No. 3 had mildly active ulcerative colitis before initiation of ipilimumab therapy and was given vedolizumab for prophylactic purpose 1 week prior to initiation of ipilimumab infusions to avoid potential aggravation of the underlying colitis disease, as opposed to induction therapy against ICPI-induced enterocolitis. Unfortunately, 


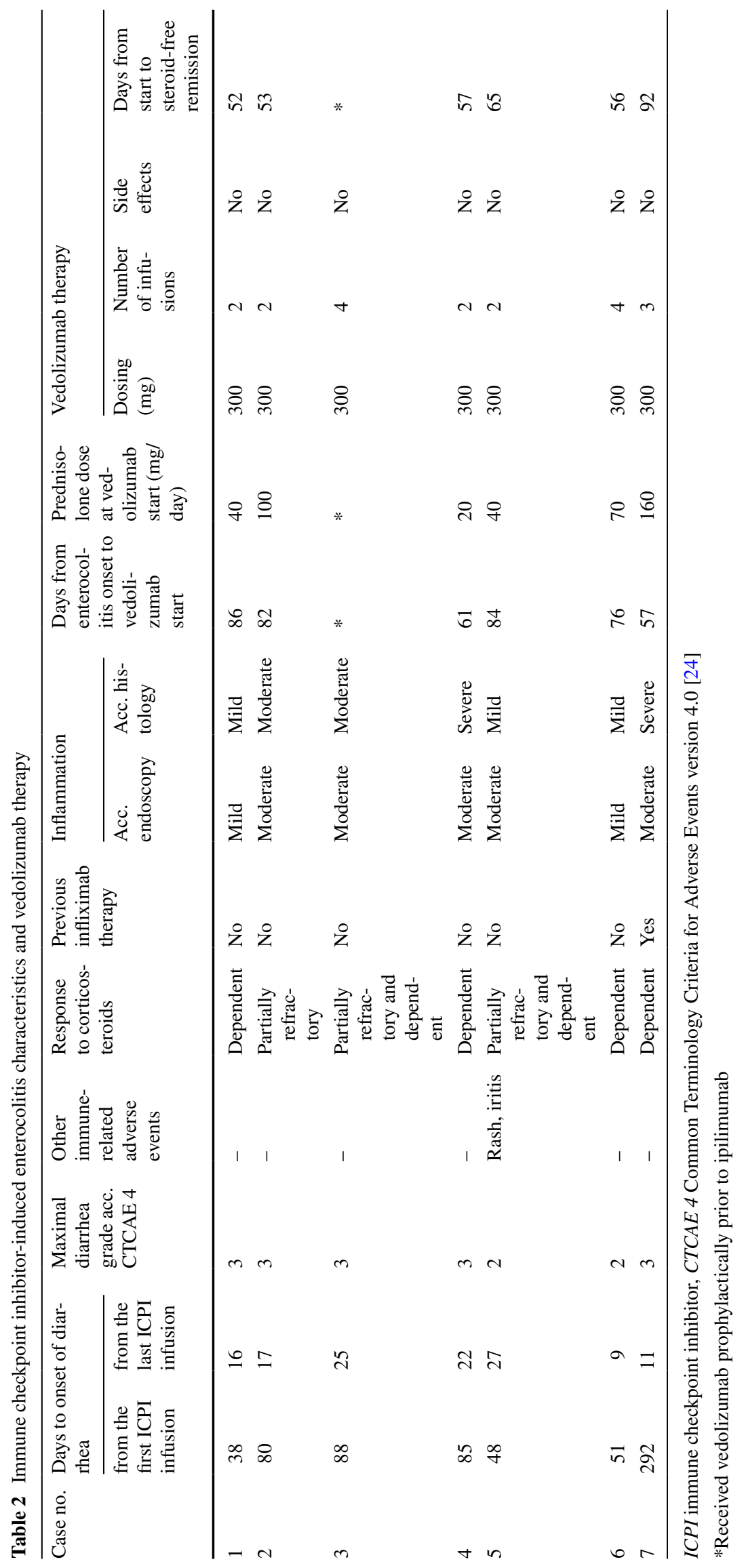



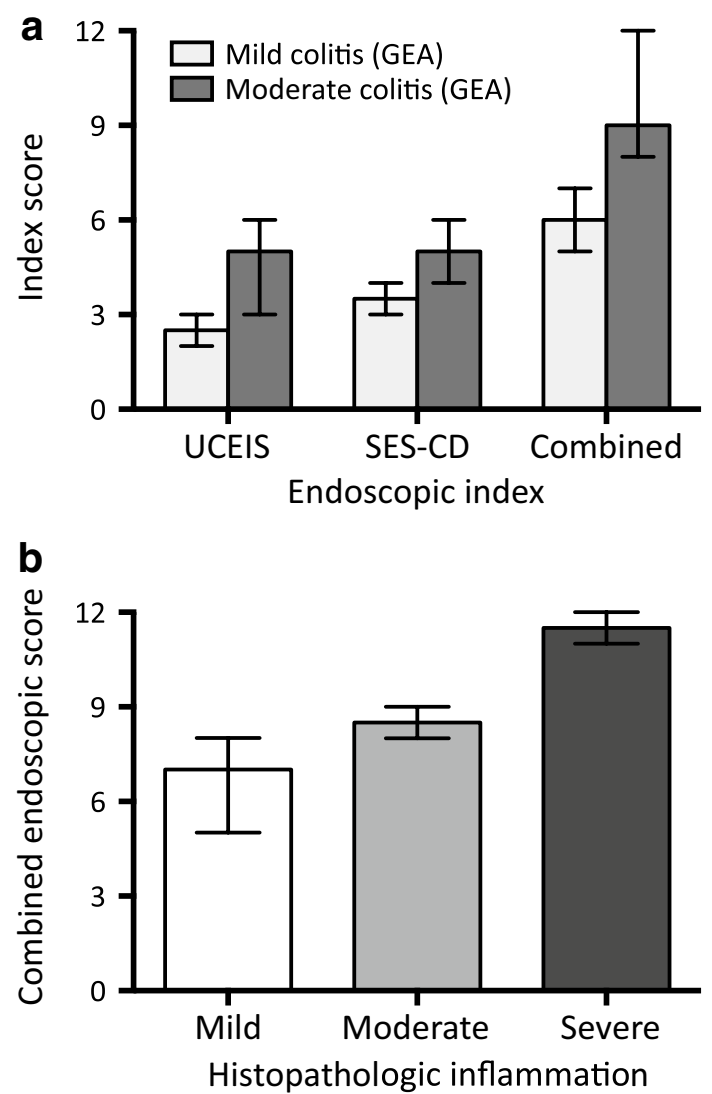

Fig. 1 Evaluation of immune checkpoint inhibitor-induced enterocolitis using endoscopic scores developed for Crohn's disease and ulcerative colitis. a Colonoscopy findings were categorized based on global endoscopic assessment (GEA) of the most inflamed segment (normal, mild, moderate, or severe inflammation), and compared to endoscopic index scores generated using the Ulcerative Colitis Endoscopic Index of Severity (UCEIS; $0-8$ points) [25], Simple Endoscopic Score for Crohn's Disease (SES-CD; 0-12 points) [26], and a combined endoscopic score (sum of individual UCEIS and SES-CD scores; 0-20 points). b Colonic mucosal histopathology was categorized into normal, mild, moderate, or severe inflammation, and compared to the combined endoscopic score. Columns and error bars represent median values \pm range

diarrheal symptoms increased markedly after the fourth ipilimumab dose and thus the desired protective effect from vedolizumab was not achieved.

Routine laboratory tests, including plasma (P) C-reactive protein (CRP), P-albumin, blood (B) neutrophils, B-lymphocytes, and F-calprotectin, were taken in all patients before, during, and after the periods when ICPI therapy and vedolizumab, respectively, were administered (Figs. 2, 3). Patient No. 3 was excluded from the analyses presented in Figs. 2 and 3 since vedolizumab in this case was given prophylactically (see above).

Median P-CRP and F-calprotectin were increased at the onset of diarrhea to $23.5 \mathrm{mg} / \mathrm{L}$ (range 1.8-154.0) and $915 \mathrm{mg} / \mathrm{kg}$ (range 228-1799), respectively, and decreased
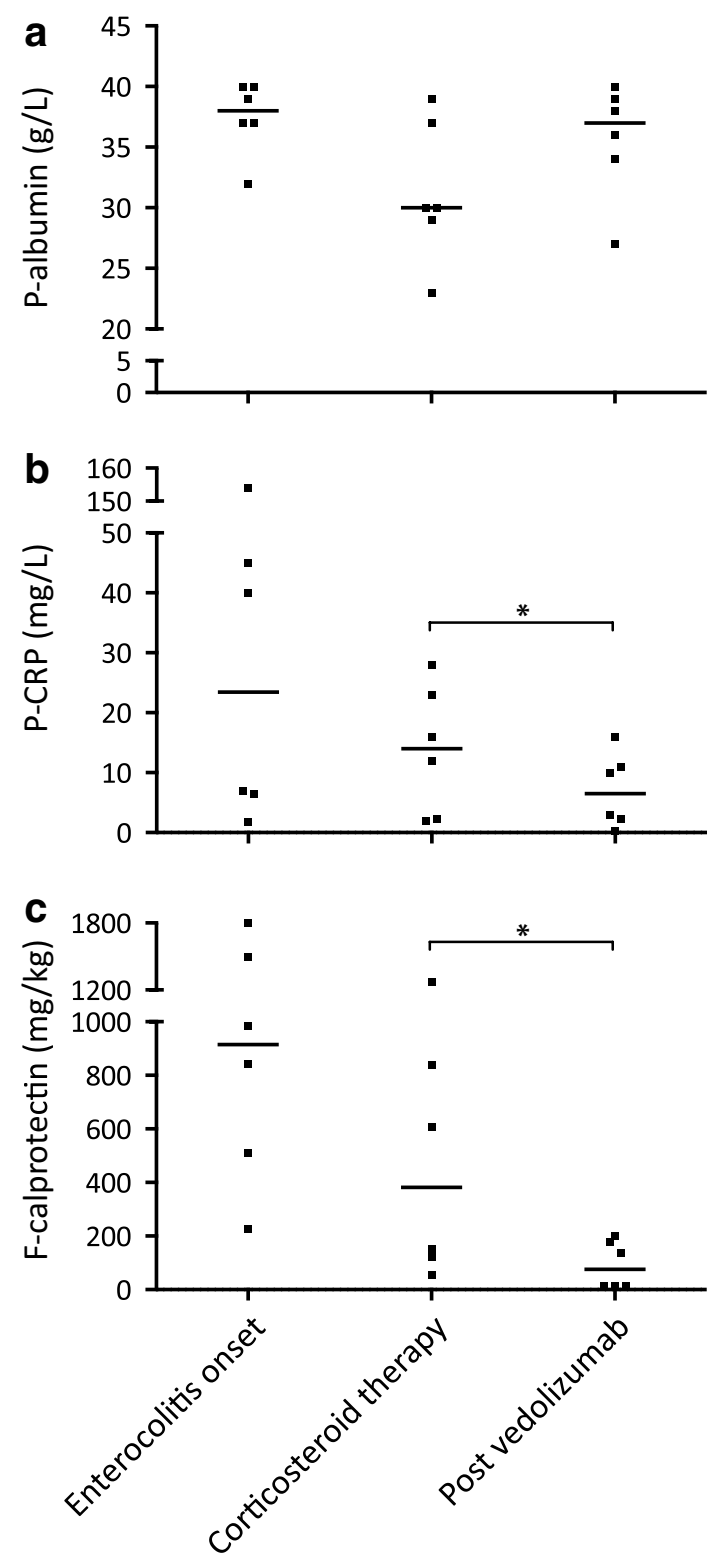

Fig. 2 Laboratory inflammatory biomarkers in patients with immune checkpoint inhibitor-induced enterocolitis, in relation to corticosteroid and vedolizumab treatment. a Plasma albumin concentrations at enterocolitis onset, during corticosteroid therapy just before starting vedolizumab, and after vedolizumab therapy. b Plasma C-reactive protein concentrations at corresponding time-points. c Fecal calprotectin concentrations at corresponding time-points. Enterocolitis onset: at onset of ICPI-induced enterocolitis, Corticosteroid therapy: just prior to initiation of vedolizumab treatment, Post vedolizumab: after vedolizumab treatment and after corticosteroids had been tapered. $P$ plasma, $F$ fecal, $C R P$ C-reactive protein, $I C P I$ immune checkpoint inhibitor. Individual values and medians; $* P<0.05$ (Wilcoxon test); $n=6$ (patient No. 3, who received vedolizumab prophylactically, was excluded from this analysis)

as a result of treatment with corticosteroids to $14.0 \mathrm{mg} / \mathrm{L}$ (range 2.0-28.0) and $382 \mathrm{mg} / \mathrm{kg}$ (range 54-1268), respectively. Of note, after vedolizumab treatment, the 

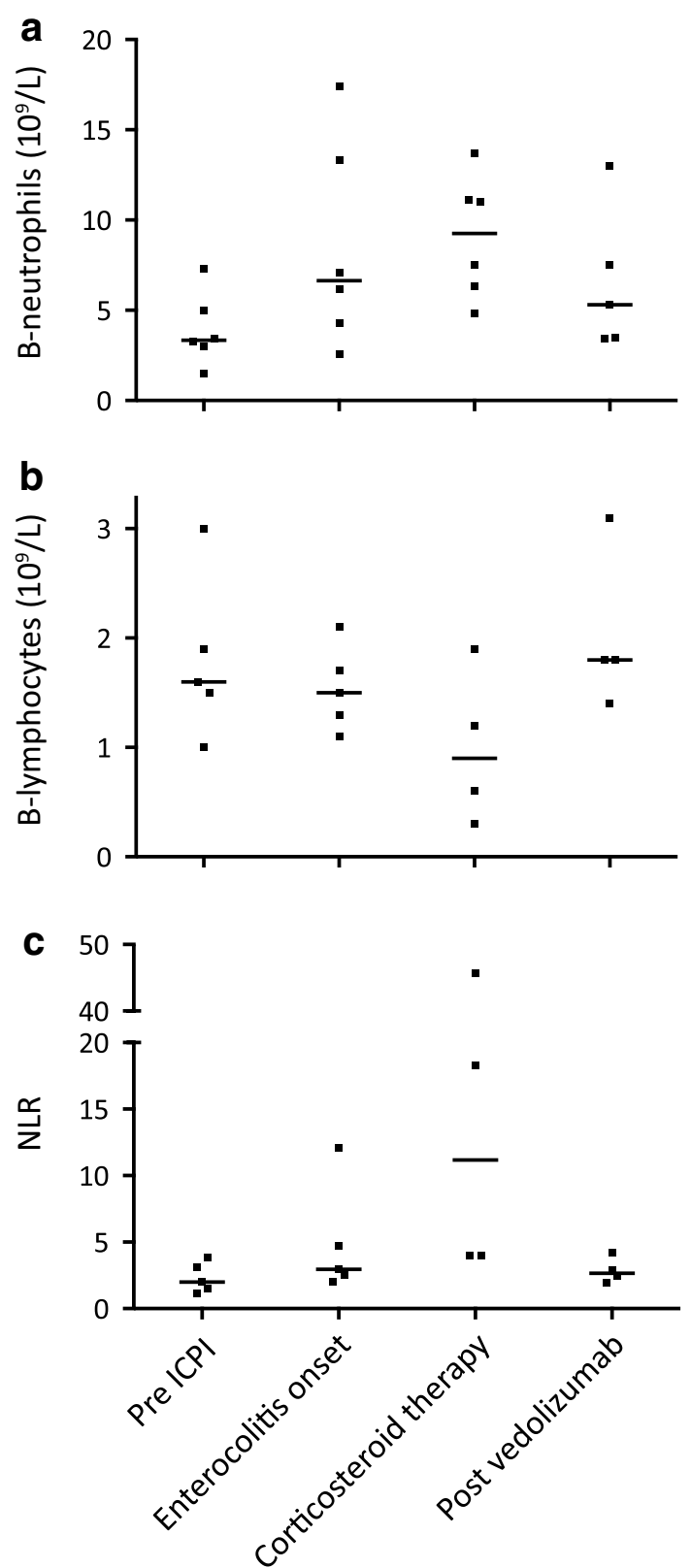

Fig. 3 Blood lymphocyte and neutrophil counts in patients with immune checkpoint inhibitor-induced enterocolitis, in relation to ICPI, corticosteroid, and vedolizumab treatment. a Blood neutrophil counts before onset of enterocolitis, at enterocolitis onset, during corticosteroid therapy just before starting vedolizumab, and after vedolizumab therapy. b Blood lymphocyte counts at corresponding time-points. $\mathbf{c}$ The blood neutrophil/lymphocyte ratio at corresponding time-points. Individual values and medians. Blood cell counts were not available in all patients. Pre ICPI: just prior to initiation of ICPI therapy, Enterocolitis onset: at onset of ICPI-induced enterocolitis, Corticosteroid therapy: just prior to initiation of vedolizumab treatment, Post vedolizumab: after vedolizumab treatment and after corticosteroids had been tapered. $B$ blood, ICPI immune checkpoint inhibitor, $N L R$ neutrophil/lymphocyte ratio levels of P-CRP and F-calprotectin decreased even further to $6.5 \mathrm{mg} / \mathrm{L}$ (range $0.3-16.0$ ) and $76 \mathrm{mg} / \mathrm{kg}$ (range 15-199) (Fig. 2b, c). In contrast, P-albumin levels decreased after treatment with corticosteroids (median $30 \mathrm{~g} / \mathrm{L}$; range 23-39) and increased after administration of vedolizumab (median $37 \mathrm{~g} / \mathrm{L}$; range 27-40) (Fig. 2a).

Examination of blood lymphocyte levels and the neutrophil/lymphocyte ratio (NLR) showed decreased levels of lymphocytes and an increase in the NLR after patients had been treated with corticosteroids (Fig. 3b, c). After vedolizumab therapy, these parameters were normalized (Fig. 3b, c).

\section{Discussion}

We report on our experience of vedolizumab as an effective and safe therapy for treating ICPI-induced enterocolitis in selected patients, based on a case series of seven patients. These results corroborate a recent report on a single patient who had developed colitis secondary to ipilimumab therapy and was successfully treated with vedolizumab [29]. The patients selected for vedolizumab therapy in our retrospective study were either steroid-dependent and/or partially steroid refractory. Management in accordance with established algorithms with corticosteroids was applied but tapering was not feasible in these patients [5]. Additional immunosuppressive therapy was required to control the enterocolitis, and these patients thus represent a group of difficult-to-treat cases. This is underscored by the fact that the patients were on futile corticosteroid therapy for a median of 79 days before vedolizumab therapy was started. However, since all patients were on corticosteroids when vedolizumab therapy was initiated, the gut inflammation and symptoms were generally mild to moderate at this point. We considered the most adequate read-out parameter with regards to vedolizumab efficacy to be steroid-free enterocolitis remission. Our findings suggest that administration of two to four infusions of vedolizumab is sufficient to achieve steroid-free remission. In our patients, this endpoint was reached within a median of 56 days from the start of vedolizumab treatment. This may be compared to recommendations advocating the use of infliximab together with a steroid-taper over 45-60 days or more in cases of steroid refractory ICPI-induced enterocolitis [4]. Considering the exhaustive attempts to control the inflammation with corticosteroids including high doses and repeated unsuccessful tapering, it is very unlikely that the inflammation would have resolved without additional immunosuppressive therapy. Vedolizumab was chosen for this purpose as infliximab was considered excessive in relation to irAE severity; moreover, there is an unclear relationship between anti-TNF $\alpha$ therapy and melanoma [30-33]. 
The diagnosis of ICPI-induced enterocolitis was confirmed endoscopically and histopathologically in all patients. It is well known that the correlation between the degree of gastrointestinal symptoms and the level of gut inflammation is often poor. Therefore, gastroenterologists aim at using structured and objective measures of inflammation for evaluation and monitoring of inflammatory gut disorders. Since ICPI-induced enterocolitis may exhibit features typical for both Crohn's disease and/or ulcerative colitis, we combined two validated scores for Crohn's disease (SES-CD) and ulcerative colitis (UCEIS), respectively, when evaluating enterocolitis in these patients. Interestingly, the combined score corresponded better to the histopathological degree of inflammation (Fig. 1b), than the global endoscopic assessment did (data not shown), suggesting that development of a specific endoscopic index for ICPI-induced enterocolitis would be useful for a more accurate grading of the inflammation. This, in turn, would be helpful in choosing and evaluating appropriate antiinflammatory therapies.

In addition to enabling corticosteroid tapering, vedolizumab treatment led to a notable reduction in the levels of F-calprotectin and P-CRP, reflecting the attenuated inflammation in the gut. This was supported by a normalizing trend in P-albumin. The changes observed in blood cell counts were expected, given known effects of corticosteroids causing lymphopenia and neutrophilia [14].

There were no vedolizumab-related adverse events among our patients, which is in agreement with the documented favorable safety profile of vedolizumab. Results from six clinical trials for IBD comprising 2830 patients and 4811 person-years of vedolizumab exposure have not shown any increased risks of infections, serious infections including PML, malignancies, or infusion-related reactions over placebo [16, 17, 21]. Among the various immunosuppressants, systemic corticosteroids show the strongest association with serious infections, but the risk increases steeply when systemically immunsuppressive agents are combined [34-37]. It seems that serious infections in the context of infliximab therapy for irAEs are relatively rare, but nevertheless potentially fatal. There are case reports on the subject [38-40], and a retrospective study of 740 ICPItreated patients with melanoma found the rate of serious infections to be $7.3 \%$ and identified corticosteroids and/or infliximab as the main risk factors [37].

Treatment with infliximab is recommended in cases of corticosteroid refractory ICPI-induced enterocolitis [4, 41, 42]. In a recent study on 254 melanoma patients with irAEs, $29(11.4 \%)$ patients received infliximab therapy and high-dose corticosteroids [43]. Among these 29 patients, 21 patients responded to infliximab but 8 (27.6\%) did not respond and received prolonged courses of corticosteroids. There is very little data available on the effects and safety of infliximab treatment in this context and on the potential effects of corticosteroids in combination with infliximab on the anti-tumor efficacy of ICPI therapy [42]. In a retrospective study on ipilimumab-treated melanoma patients who had developed diarrhea, there was no significant difference in the median overall survival time between those treated with infliximab $(n=7)$ and those treated with corticosteroids only ( $n=29)$ [44]. However, an important aspect omitted in this type of analysis is that the median overall survival time of the infliximab-treated patient group could have been even longer had they not received infliximab. This question could be addressed in studies utilizing vedolizumab. There is an ongoing debate whether irAEs and/ or the severity of irAEs is associated with better cancerspecific outcomes, and whether treatment with immunosuppressive agents potentially counteracts the anti-tumor effect of ICPI therapy. There are several studies supporting these concepts [3, 44-49] but also those refuting them [5, 43, 44, 48, 50-52].

We believe that vedolizumab is an appropriate choice of therapy for many but not all patients with ICPI-induced enterocolitis. For instance, patients with extraintestinal irAEs may require systemic immunosuppression rather than vedolizumab which has a gut-specific effect. In our material, only one out of seven patients (14\%) had additional irAEs, and in a larger published cohort, this proportion was $37 \%$ [53]. As illustrated by patient No. 7, vedolizumab may also be used as second-line therapy in infliximab-refractory cases, which is true in IBD as well [22]. In addition, vedolizumab may be considered when contraindications to infliximab prevail or when infliximab is not tolerated. In one of the patients, vedolizumab was administered prophylactically to prevent a flare of preexisting and mildly active UC. Unfortunately, this was not successful; this could speak against vedolizumab being efficacious in this type of scenario. But given that this was a single case, the concept of prophylactic vedolizumab therapy in patients with known IBD should be explored in larger studies. Interestingly, there are reports on patients with IBD who received ipilimumab without increased disease activity [54]. Other situations where prophylactic treatment with vedolizumab could be suggested are (a) combination treatment with ipilimumab and a PD-1 inhibitor where the risk of severe enterocolitis is increased [3], and (b) adjuvant ICPI therapy in high-risk resected melanoma where the acceptance for irAEs may be decreased given an apparent lack of malignant disease [9]. Taken together, patients that we consider suitable for vedolizumab treatment are those with steroid-dependent and/or partially refractory mild to moderate enterocolitis, and without extraintestinal irAEs that require additional immunosuppression. In contrast, patients with severe gut 
inflammation that demands urgent measures should be considered for other therapies such as infliximab or, as last resort, colectomy.

In conclusion, this is the first case series to suggest that vedolizumab is an effective and well-tolerated therapy for steroid refractory and/or dependent enterocolitis caused by treatment with ipilimumab or nivolumab. In addition to these, and pembrolizumab, there are several new ICPI agents being subjected to clinical evaluation in numerous types of malignancies, and subsequently the prevalence of ICPI-induced enterocolitis may be expected to increase considerably in the near future. Thus, there is a growing need for developing evidence-based and increasingly optimized irAE management algorithms, taking the long-term cancer-treatment strategy and the overall survival into account.

Acknowledgements The authors thank Dr. Nancy Eik-Nes for professional language editing of the manuscript. We also thank the staff at the endoscopy unit and the outpatient clinic at the Section for Gastroenterology (Skane University Hospital), and the staff at the outpatient clinics at the Department of Oncology and the Department of Respiratory Medicine (Skane University Hospital), for their work with the patients and their work with supporting the study.

Funding The study was supported by the Hedlund Foundation, Österlund Foundation, Julin Foundation, Royal Physiographic Society of Lund, Swedish Society of Medicine (SLS), Research Support from the Healthcare Region of Southern Sweden, and by Grants to researchers in the public health care from the Swedish government (ALFSKANE-539811) to JM.

\section{Compliance with ethical standards}

Conflict of interest A. Carneiro has received honoraria for educational activities from BMS; E. Hertervig has received speaker and consultant honoraria from AbbVie, MSD, Takeda; H. Griph has received honoraria for educational activities from BMS; J. Marsal has received honoraria for educational activities from BMS, speaker and consultant honoraria from AbbVie, Ferring, Hospira, MSD, Pfizer, Takeda, Tillotts, UCB-Pharma, and research grants from AbbVie, Ferring, Hospira. The other authors declare that they have no conflicts of interest.

Ethical approval The study was approved by the regional ethics committee in Lund, Sweden (reference No. 2016/624). No patient consent was required as this was a retrospective study. The study was performed in accordance with the ethical standards of the 1964 Helsinki declaration and its later amendments.

Open Access This article is distributed under the terms of the Creative Commons Attribution 4.0 International License (http:// creativecommons.org/licenses/by/4.0/), which permits unrestricted use, distribution, and reproduction in any medium, provided you give appropriate credit to the original author(s) and the source, provide a link to the Creative Commons license, and indicate if changes were made.

\section{References}

1. Buchbinder EI, Desai A (2016) CTLA-4 and PD-1 pathways: similarities, differences, and implications of their inhibition. Am J Clin Oncol 39(1):98-106. doi:10.1097/ COC. 000000000000239

2. Romano E, Kusio-Kobialka M, Foukas PG, Baumgaertner P, Meyer C, Ballabeni P, Michielin O, Weide B, Romero P, Speiser DE (2015) Ipilimumab-dependent cell-mediated cytotoxicity of regulatory $\mathrm{T}$ cells ex vivo by nonclassical monocytes in melanoma patients. Proc Natl Acad Sci USA 112(19):6140-6145. doi:10.1073/pnas.1417320112

3. Larkin J, Chiarion-Sileni V, Gonzalez R, Grob JJ, Cowey CL, Lao CD, Schadendorf D, Dummer R, Smylie M, Rutkowski P, Ferrucci PF, Hill A, Wagstaff J, Carlino MS, Haanen JB, Maio M, Marquez-Rodas I, McArthur GA, Ascierto PA, Long GV, Callahan MK, Postow MA, Grossmann K, Sznol M, Dreno B, Bastholt L, Yang A, Rollin LM, Horak C, Hodi FS, Wolchok JD (2015) Combined nivolumab and ipilimumab or monotherapy in untreated melanoma. N Engl J Med 373(1):23-34. doi:10.1056/ NEJMoa1504030

4. Weber JS, Kahler KC, Hauschild A (2012) Management of immune-related adverse events and kinetics of response with ipilimumab. J Clin Oncol 30(21):2691-2697. doi:10.1200/ JCO.2012.41.6750

5. Spain L, Diem S, Larkin J (2016) Management of toxicities of immune checkpoint inhibitors. Cancer Treat Rev 44:51-60. doi:10.1016/j.ctrv.2016.02.001

6. Kwon ED, Drake CG, Scher HI, Fizazi K, Bossi A, van den Eertwegh AJ, Krainer M, Houede N, Santos R, Mahammedi H, Ng S, Maio M, Franke FA, Sundar S, Agarwal N, Bergman AM, Ciuleanu TE, Korbenfeld E, Sengelov L, Hansen S, Logothetis C, Beer TM, McHenry MB, Gagnier P, Liu D, Gerritsen WR, Investigators CA (2014) Ipilimumab versus placebo after radiotherapy in patients with metastatic castration-resistant prostate cancer that had progressed after docetaxel chemotherapy (CA184-043): a multicentre, randomised, double-blind, phase 3 trial. Lancet Oncol 15(7):700-712. doi:10.1016/S1470-2045(14)70189-5

7. Eggermont AM, Chiarion-Sileni V, Grob JJ, Dummer R, Wolchok JD, Schmidt H, Hamid O, Robert C, Ascierto PA, Richards JM, Lebbe C, Ferraresi V, Smylie M, Weber JS, Maio M, Konto C, Hoos A, de Pril V, Gurunath RK, de Schaetzen G, Suciu S, Testori A (2015) Adjuvant ipilimumab versus placebo after complete resection of high-risk stage III melanoma (EORTC 18071): a randomised, double-blind, phase 3 trial. Lancet Oncol 16(5):522-530. doi:10.1016/S1470-2045(15)70122-1

8. Robert C, Schachter J, Long GV, Arance A, Grob JJ, Mortier L, Daud A, Carlino MS, McNeil C, Lotem M, Larkin J, Lorigan P, Neyns B, Blank CU, Hamid O, Mateus C, Shapira-Frommer R, Kosh M, Zhou H, Ibrahim N, Ebbinghaus S, Ribas A, investigators K- (2015) Pembrolizumab versus Ipilimumab in advanced melanoma. N Engl J Med 372(26):2521-2532. doi:10.1056/ NEJMoa1503093

9. Spain L, Larkin J (2016) Weighing up the pros and cons of immune checkpoint inhibitors in the treatment of melanoma. Immunotherapy 8 (6):677-679. doi:10.2217/imt.16.6

10. Poullis A, Foster R, Mendall MA, Fagerhol MK (2003) Emerging role of calprotectin in gastroenterology. J Gastroenterol Hepatol 18(7):756-762

11. Langhorst J, Elsenbruch S, Koelzer J, Rueffer A, Michalsen A, Dobos GJ (2008) Noninvasive markers in the assessment of intestinal inflammation in inflammatory bowel diseases: performance of fecal lactoferrin, calprotectin, and PMN-elastase, CRP, and clinical indices. Am J Gastroenterol 103(1):162-169. doi:10.1111/j.1572-0241.2007.01556.x 
12. Templeton AJ, McNamara MG, Seruga B, Vera-Badillo FE, Aneja P, Ocana A, Leibowitz-Amit R, Sonpavde G, Knox JJ, Tran B, Tannock IF, Amir E (2014) Prognostic role of neutrophil-to-lymphocyte ratio in solid tumors: a systematic review and meta-analysis. J Natl Cancer Inst 106(6):dju124. doi:10.1093/jnci/dju124

13. Callahan MK, Wolchok JD, Allison JP (2010) Anti-CTLA-4 antibody therapy: immune monitoring during clinical development of a novel immunotherapy. Semin Oncol 37(5):473-484. doi:10.1053/j.seminoncol.2010.09.001

14. Gruver-Yates AL, Cidlowski JA (2013) Tissue-specific actions of glucocorticoids on apoptosis: a double-edged sword. Cells 2(2):202-223. doi:10.3390/cells2020202

15. Levin AD, Wildenberg ME, van den Brink GR (2016) Mechanism of action of anti-TNF therapy in inflammatory bowel disease. J Crohns Colitis 10(8):989-997. doi:10.1093/ecco-jcc/ jjw053

16. Sandborn WJ, Feagan BG, Rutgeerts $P$, Hanauer S, Colombel JF, Sands BE, Lukas M, Fedorak RN, Lee S, Bressler B, Fox I, Rosario M, Sankoh S, Xu J, Stephens K, Milch C, Parikh A, Group GS (2013) Vedolizumab as induction and maintenance therapy for Crohn's disease. N Engl J Med 369(8):711-721. doi:10.1056/NEJMoa1215739

17. Feagan BG, Rutgeerts P, Sands BE, Hanauer S, Colombel JF, Sandborn WJ, Van Assche G, Axler J, Kim HJ, Danese S, Fox I, Milch C, Sankoh S, Wyant T, Xu J, Parikh A, Group GS (2013) Vedolizumab as induction and maintenance therapy for ulcerative colitis. N Engl J Med 369(8):699-710. doi:10.1056/ NEJMoa1215734

18. Berlin C, Berg EL, Briskin MJ, Andrew DP, Kilshaw PJ, Holzmann B, Weissman IL, Hamann A, Butcher EC (1993) Alpha 4 beta 7 integrin mediates lymphocyte binding to the mucosal vascular addressin MAdCAM-1. Cell 74(1):185-195

19. Soler D, Chapman T, Yang LL, Wyant T, Egan R, Fedyk ER (2009) The binding specificity and selective antagonism of vedolizumab, an anti-alpha4beta7 integrin therapeutic antibody in development for inflammatory bowel diseases. J Pharmacol Exp Ther 330(3):864-875. doi:10.1124/jpet.109.153973

20. Wyant T, Fedyk E, Abhyankar B (2016) An Overview of the mechanism of action of the monoclonal antibody vedolizumab. J Crohns Colitis 10(12):1437-1444. doi:10.1093/ecco-jcc/ jjw092

21. Colombel JF, Sands BE, Rutgeerts P, Sandborn W, Danese S, D'Haens G, Panaccione R, Loftus EV Jr, Sankoh S, Fox I, Parikh A, Milch C, Abhyankar B, Feagan BG (2016) The safety of vedolizumab for ulcerative colitis and Crohn's disease. Gut. doi:10.1136/gutjnl-2015-311079

22. Bryant RV, Sandborn WJ, Travis SP (2015) Introducing vedolizumab to clinical practice: who, when, and how? J Crohns Colitis 9(4):356-366. doi:10.1093/ecco-jcc/jjv033

23. von Roon AC, Karamountzos L, Purkayastha S, Reese GE, Darzi AW, Teare JP, Paraskeva P, Tekkis PP (2007) Diagnostic precision of fecal calprotectin for inflammatory bowel disease and colorectal malignancy. Am J Gastroenterol 102(4):803-813. doi:10.1111/j.1572-0241.2007.01126.x

24. Common Terminology Criteria for Adverse Events (CTCAE), Version 4.0. (U.S. Department of Health and Human Services; National Institutes of Health; National Cancer Institute; 2010). http://evs.nci.nih.gov/ftp1/CTCAE/CTCAE_4.03_2010-06-14_ QuickReference_8.5x11.pdf

25. Travis SP, Schnell D, Krzeski P, Abreu MT, Altman DG, Colombel JF, Feagan BG, Hanauer SB, Lichtenstein GR, Marteau PR, Reinisch W, Sands BE, Yacyshyn BR, Schnell P, Bernhardt CA, Mary JY, Sandborn WJ (2013) Reliability and initial validation of the ulcerative colitis endoscopic index of severity. Gastroenterology 145(5):987-995. doi:10.1053/j.gastro.2013.07.024
26. Daperno M, D’Haens G, Van Assche G, Baert F, Bulois P, Maunoury V, Sostegni R, Rocca R, Pera A, Gevers A, Mary JY, Colombel JF, Rutgeerts P (2004) Development and validation of a new, simplified endoscopic activity score for Crohn's disease: the SES-CD. Gastrointest Endosc 60(4):505-512

27. Travis SP, Schnell D, Feagan BG, Abreu MT, Altman DG, Hanauer SB, Krzeski P, Lichtenstein GR, Marteau PR, Mary JY, Reinisch W, Sands BE, Schnell P, Yacyshyn BR, Colombel JF, Bernhardt CA, Sandborn WJ (2015) The impact of clinical information on the assessment of endoscopic activity: characteristics of the ulcerative colitis endoscopic index of severity [UCEIS]. J Crohns Colitis 9(8):607-616. doi:10.1093/ecco-jcc/jjv077

28. Oken MM, Creech RH, Tormey DC, Horton J, Davis TE, McFadden ET, Carbone PP (1982) Toxicity and response criteria of the eastern cooperative oncology group. Am J Clin Oncol 5(6):649-655

29. Hsieh AH, Ferman M, Brown MP, Andrews JM (2016) Vedolizumab: a novel treatment for ipilimumab-induced colitis. BMJ Case Rep 2016. doi:10.1136/bcr-2016-216641

30. Long MD, Martin CF, Pipkin CA, Herfarth HH, Sandler RS, Kappelman MD (2012) Risk of melanoma and nonmelanoma skin cancer among patients with inflammatory bowel disease. Gastroenterology 143 (2):390-399. doi:10.1053/j. gastro.2012.05.004

31. Mariette X, Matucci-Cerinic M, Pavelka K, Taylor P, van Vollenhoven R, Heatley R, Walsh C, Lawson R, Reynolds A, Emery $P$ (2011) Malignancies associated with tumour necrosis factor inhibitors in registries and prospective observational studies: a systematic review and meta-analysis. Ann Rheum Dis 70(11):1895-1904. doi:10.1136/ard.2010.149419

32. Raaschou P, Simard JF, Holmqvist M, Askling J, Group AS (2013) Rheumatoid arthritis, anti-tumour necrosis factor therapy, and risk of malignant melanoma: nationwide population based prospective cohort study from Sweden. BMJ 346:f1939. doi:10.1136/bmj.f1939

33. Wolfe F, Michaud K (2007) Biologic treatment of rheumatoid arthritis and the risk of malignancy: analyses from a large US observational study. Arthritis Rheum 56(9):2886-2895. doi:10.1002/art.22864

34. Bongartz T, Sutton AJ, Sweeting MJ, Buchan I, Matteson EL, Montori V (2006) Anti-TNF antibody therapy in rheumatoid arthritis and the risk of serious infections and malignancies: systematic review and meta-analysis of rare harmful effects in randomized controlled trials. JAMA 295(19):2275-2285. doi:10.1001/jama.295.19.2275

35. Marehbian J, Arrighi HM, Hass S, Tian H, Sandborn WJ (2009) Adverse events associated with common therapy regimens for moderate-to-severe Crohn's disease. Am J Gastroenterol 104(10):2524-2533. doi:10.1038/ajg.2009.322

36. Toruner M, Loftus EV Jr, Harmsen WS, Zinsmeister AR, Orenstein R, Sandborn WJ, Colombel JF, Egan LJ (2008) Risk factors for opportunistic infections in patients with inflammatory bowel disease. Gastroenterology 134(4):929-936. doi:10.1053/j. gastro.2008.01.012

37. Del Castillo M, Romero FA, Arguello E, Kyi C, Postow MA, Redelman-Sidi G (2016) The spectrum of serious infections among patients receiving immune checkpoint blockade for the treatment of melanoma. Clin Infect Dis 63(11):1490-1493. doi:10.1093/cid/ciw539

38. Lord JD, Hackman RC, Moklebust A, Thompson JA, Higano CS, Chielens D, Steinbach G, McDonald GB (2010) Refractory colitis following anti-CTLA4 antibody therapy: analysis of mucosal FOXP3 + T cells. Dig Dis Sci 55(5):1396-1405. doi:10.1007/ s10620-009-0839-8

39. Kyi C, Hellmann MD, Wolchok JD, Chapman PB, Postow MA (2014) Opportunistic infections in patients treated 
with immunotherapy for cancer. J Immunother Cancer 2:19. doi:10.1186/2051-1426-2-19

40. Arriola E, Wheater M, Krishnan R, Smart J, Foria V, Ottensmeier C (2015) Immunosuppression for ipilimumab-related toxicity can cause pneumocystis pneumonia but spare antitumor immune control. Oncoimmunology 4(10):e1040218. doi:10.108 0/2162402X.2015.1040218

41. Beck KE, Blansfield JA, Tran KQ, Feldman AL, Hughes MS, Royal RE, Kammula US, Topalian SL, Sherry RM, Kleiner D, Quezado M, Lowy I, Yellin M, Rosenberg SA, Yang JC (2006) Enterocolitis in patients with cancer after antibody blockade of cytotoxic T-lymphocyte-associated antigen 4. J Clin Oncol 24(15):2283-2289. doi:10.1200/JCO.2005.04.5716

42. Pages C, Gornet JM, Monsel G, Allez M, Bertheau P, Bagot M, Lebbe C, Viguier M (2013) Ipilimumab-induced acute severe colitis treated by infliximab. Melanoma Res 23(3):227-230. doi:10.1097/CMR.0b013e32835fb524

43. Horvat TZ, Adel NG, Dang TO, Momtaz P, Postow MA, Callahan MK, Carvajal RD, Dickson MA, D'Angelo SP, Woo KM, Panageas KS, Wolchok JD, Chapman PB (2015) Immune-related adverse events, need for systemic immunosuppression, and effects on survival and time to treatment failure in patients with melanoma treated with ipilimumab at memorial sloan kettering cancer center. J Clin Oncol 33(28):3193-3198. doi:10.1200/ JCO.2015.60.8448

44. Arriola E, Wheater M, Karydis I, Thomas G, Ottensmeier C (2015) Infliximab for IPILIMUMAB-related colitis-letter. Clin Cancer Res 21(24):5642-5643. doi:10.1158/1078-0432. CCR-15-2471

45. Attia P, Phan GQ, Maker AV, Robinson MR, Quezado MM, Yang JC, Sherry RM, Topalian SL, Kammula US, Royal RE, Restifo NP, Haworth LR, Levy C, Mavroukakis SA, Nichol G, Yellin MJ, Rosenberg SA (2005) Autoimmunity correlates with tumor regression in patients with metastatic melanoma treated with anti-cytotoxic T-lymphocyte antigen-4. J Clin Oncol 23(25):6043-6053. doi:10.1200/JCO.2005.06.205

46. Yang JC, Hughes M, Kammula U, Royal R, Sherry RM, Topalian SL, Suri KB, Levy C, Allen T, Mavroukakis S, Lowy I, White DE, Rosenberg SA (2007) Ipilimumab (anti-CTLA4 antibody) causes regression of metastatic renal cell cancer associated with enteritis and hypophysitis. J Immunother 30(8):825-830. doi:10.1097/CJI.0b013e318156e47e

47. Yousaf N, Davidson M, Goode E, Thomas C, Hung R, Gore M, Larkin J (2015) The cost of ipilimumab toxicity: a single-centre analysis. Melanoma Res 25(3):259-264. doi:10.1097/CMR.0000000000000158

48. Downey SG, Klapper JA, Smith FO, Yang JC, Sherry RM, Royal RE, Kammula US, Hughes MS, Allen TE, Levy CL, Yellin M, Nichol G, White DE, Steinberg SM, Rosenberg SA (2007) Prognostic factors related to clinical response in patients with metastatic melanoma treated by CTL-associated antigen-4 blockade. Clin Cancer Res 13(22):6681-6688. doi:10.1158/1078-0432. CCR-07-0187

49. Feng Y, Roy A, Masson E, Chen TT, Humphrey R, Weber JS (2013) Exposure-response relationships of the efficacy and safety of ipilimumab in patients with advanced melanoma. Clin Cancer Res 19(14):3977-3986. doi:10.1158/1078-0432.CCR-12-3243

50. De Felice KM, Gupta A, Rakshit S, Khanna S, Kottschade LA, Finnes HD, Papadakis KA, Loftus EV Jr, Raffals LE, Markovic SN (2015) Ipilimumab-induced colitis in patients with metastatic melanoma. Melanoma Res 25(4):321-327. doi:10.1097/ CMR.0000000000000165

51. Prieto PA, Yang JC, Sherry RM, Hughes MS, Kammula US, White DE, Levy CL, Rosenberg SA, Phan GQ (2012) CTLA-4 blockade with ipilimumab: long-term follow-up of 177 patients with metastatic melanoma. Clin Cancer Res 18(7):2039-2047. doi:10.1158/1078-0432.CCR-11-1823

52. Wolchok JD, Neyns B, Linette G, Negrier S, Lutzky J, Thomas L, Waterfield W, Schadendorf D, Smylie M, Guthrie T Jr, Grob JJ, Chesney J, Chin K, Chen K, Hoos A, O’Day SJ, Lebbe C (2010) Ipilimumab monotherapy in patients with pretreated advanced melanoma: a randomised, double-blind, multicentre, phase 2, dose-ranging study. Lancet Oncol 11(2):155-164. doi:10.1016/S1470-2045(09)70334-1

53. Verschuren EC, van den Eertwegh AJ, Wonders J, Slangen RM, van Delft F, van Bodegraven A, Neefjes-Borst A, de Boer NK (2016) Clinical, endoscopic, and histologic characteristics of ipilimumab-associated colitis. Clin Gastroenterol Hepatol 14(6):836-842. doi:10.1016/j.cgh.2015.12.028

54. Johnson DB, Sullivan RJ, Ott PA, Carlino MS, Khushalani NI, Ye F, Guminski A, Puzanov I, Lawrence DP, Buchbinder EI, Mudigonda T, Spencer K, Bender C, Lee J, Kaufman HL, Menzies AM, Hassel JC, Mehnert JM, Sosman JA, Long GV, Clark JI (2016) Ipilimumab therapy in patients with advanced melanoma and preexisting autoimmune disorders. JAMA Oncol 2(2):234240. doi:10.1001/jamaoncol.2015.4368 